\title{
Hospital culture and clinical performance: where next?
}

Russell Mannion, Judith Smith

Health Services Management Centre, University of Birmingham, Birmingham, UK

\section{Correspondence to} Professor Russell Mannion, Health Services Management Centre, University of

Birmingham, Birmingham B15 2RT, UK;

R.mannion@bham.ac.uk

Accepted 5 December 2017 Published Online First 20 December 2017

\section{SLinked}

http://dx.doi.org/10.1136/ bmjqs-2017-006574

- http://dx.doi.org/10.1136/ bmjqs-2017-006989

Check for updates

To cite: Mannion R, Smith J. BMJ Qual Saf

2018:27:179-181.
Contemporary health policies frequently invoke notions of 'culture' and 'cultural change' as levers for achieving performance improvement and good-quality healthcare. ${ }^{1}$ But it has remained unclear whether talk of culture is largely empty rhetoric or whether framing healthcare organisations in 'cultural' terms offers useful insights that might improve organisational processes and outcomes of care. When considering the role of organisational culture in facilitating highquality care and improved outcomes, a first important step is to explain what is meant by organisational culture, and then consider the evidence that organisational culture can be purposively managed and form part of efforts to improve quality and clinical performance in healthcare delivery organisations.

A recent systematic review found a consistent association between positive organisational and workplace cultures and beneficial clinical outcomes, including reduced mortality rates across a variety of health settings. ${ }^{2}$ Most 'included' studies in the review consisted of observational and cross-sectional designs, and only four were intervention studies. It is therefore very timely that two linked articles in this issue of the journal draw on an interventionist study design and present fresh empirical evidence for a culture-clinical outcome relationship in hospital settings.

Leslie Curry and colleagues ${ }^{3}$ conducted a 2-year, mixed-methods, prospective interventionist study (Leadership Saves Lives) designed to promote positive changes in organisational culture in 10 hospitals in the USA. Quantitative changes in organisational culture were measured using a validated 31-item survey instrument (reflecting five subscales of domains of culture aggregated into an overall score) and qualitative changes were explored via in-depth interviews.
The study found that the magnitude and depth of measured changes in culture over the 2-year period varied substantially between hospitals. For example, in four of the hospitals there was no statistically significant or qualitative change in culture. In the six hospitals that experienced substantial positive cultural shifts, changes were most prominent in three domains of culture (learning environment, senior management support and psychological safety). Crucially, those hospitals with marked positive shifts in culture experienced significantly greater decreases in risk-standardised mortality rates compared with those that had not changed their culture and compared with mean changes in risk-standardised mortality rates for patients with myocardial infarction nationally. Based on these findings, the authors conclude that hospital culture may be positively influenced and that investing in strategies to foster cultures that are supportive of high performance may help hospitals in their efforts to significantly improve clinical outcomes.

Drilling deeper into these issues and based on rich qualitative data collection and analysis, the same research team $^{4}$ explored what organisational factors characterised those hospitals that succeeded in shifting culture and reducing 30-day risk-standardised mortality after acute myocardial infarction through their participation in the Leadership Saves Lives collaborative. They found that the experience of the 'guiding coalitions' (multidisciplinary teams specifically created to guide the collaborative efforts in each hospital) varied markedly across the 10 hospitals. In the six hospitals that achieved substantial positive shifts in culture, the following characteristics were evident: (1) representation of staff from different disciplines and levels in the organisational hierarchy, (2) authentic 
participation and engagement of diverse perspectives in the work of the guiding coalition, and (3) distinct patterns of managing conflict, fatigue and motivation over time.

By contrast, in the four hospitals that did not experience shifts in culture, there were particular challenges in recruiting and retaining diverse staff to the guiding coalition, the participation of staff who did attend was judged to be superficial, and there was difficulty managing conflict, blame or boredom within the guiding coalition. The authors argue that these findings suggest that careful attention need to be paid to construction and activities of such coalitions if hospitals are to maximise the benefits of participating in quality collaboratives.

That hospital culture and performance are linked and that the purposeful management of culture is possible are both substantiated by these studies. The findings reinforce messages from research in the UK that has similarly explored the relationship between hospital culture and healthcare quality and performance. ${ }^{5}$ These new studies benefit from an intervention design that enhances the credibility of the findings for policy and practice. As the phenomena examined in such research are essentially dynamic (organisational culture and performance), longitudinal studies offer important and much-needed additional insights over cross-sectional designs. We suggest that future research exploring the complex interlinkages between hospital culture and clinical performance would benefit from a number of design and methodological features.

First, drawing on the powerful example of the work reported in this issue, studies should be mixed-method, drawing on both quantitative ${ }^{56}$ and qualitative traditions. ${ }^{7}$ Ethnographic approaches are particularly suitable for addressing the sensitive and contextual-specific issues required to unravel complex cultureperformance interlinkages in fast-changing healthcare settings. ${ }^{89}$ Second, the field remains theoretically and conceptually underdeveloped, and a closer relationship between theories derived from the social and organisation sciences and empirical health services research would strengthen the credibility of prescriptions for how hospitals and their leadership teams might improve organisational governance of clinical performance. ${ }^{1011}$ Third, we are in need of better and more bespoke tools, instruments and methods for assessing culture and cultures change across different healthcare settings, building on those used by Curry et al and Bradley et al in the new research reported here, and other recent work examining hospital culture and care outcomes. ${ }^{12-14}$

Fourth, in large complex healthcare organisations, organisational culture is rarely uniform, homogeneous or coherent. Although some cultural attributes may be represented across the organisation, others may be found only in particular subcultures, often divided along lines of occupation and clinical specialisation-or even a particular space. Any research exploring culture in healthcare organisations therefore needs to explore how subcultures may vary in terms of their values and how at different times they may be driving forces for change, overt defenders of the status quo, or covert countercultures quietly undermining new initiatives. ${ }^{15}$

So what are policy makers, boards and clinical leaders of hospitals to draw from this new research into organisational culture and healthcare outcomes? One important lesson is that hospital cultures have some sort of impact on the work of clinical teams and departments, and in turn on the quality and outcome of care given to patients. In other words, the approach taken by senior managers and leaders does appear to matter: if 'wrongheaded' or dysfunctional, it can potentially add to the risk of harm. Next, these findings from the USA give clues as to what elements of 'culture' need attention to by hospital leaders and boards. They include, but are not limited to, fostering a learning environment, offering sustained and visible senior management support to clinical teams and services, and ensuring that staff across the organisation feel 'psychologically safe' and able to speak up when things are felt to be going wrong. ${ }^{16}$ Finally, these new studies show the rich and deep insights that can be gained from longitudinal, mixedmethods research that draws on the best of organisation studies research, medical sociology and health services research. ${ }^{17}$

Contributor RM and JS contributed equally to the writing of this article.

\section{Competing interests None declared.}

Provenance and peer review Commissioned; internally peer reviewed.

(C) Article author(s) (or their employer(s) unless otherwise stated in the text of the article) 2018. All rights reserved. No commercial use is permitted unless otherwise expressly granted.

\section{REFERENCES}

1 Mannion R, Davies H, Marshall M. Cultures for performance in health care. Buckingham: Open University Press, 2005.

2 Braithwaite J, Herkes J, Ludlow K, et al. Association between organisational and workplace cultures, and patient outcomes: systematic review. BMJ Open 2017;7:e017708.

3 Curry LA, Brault MA, Linnander EL, et al. Influencing organisational culture to improve hospital performance in care of patients with acute myocardial infarction: a mixed-methods intervention study. BMJ Qual Saf 2018;27:207-17.

4 Bradley EH, Brewster AL, McNatt Z, et al. How guiding coalitions promote positive culture change in hospitals: a longitudinal mixed methods interventional study. BMJ Qual Saf 2018;27:218-25.

5 Jacobs R, Mannion R, Davies HT, et al. The relationship between organizational culture and performance in acute hospitals. Soc Sci Med 2013;76:115-25.

6 Wagner C, Mannion R, Hammer A, et al. The associations between organizational culture, organizational structure and 
quality management in European hospitals. Int J Qual Health Care 2014;26 Suppl 1 (Suppl 1):74-80.

7 Mannion R, Davies H, Marshall M. Cultural attributes of 'high' and 'low' performing hospitals. J of Health Org and Management 2005;19:431-9.

8 Waring J, Jones L. Maintaining the link between methodology and method in ethnographic health research. BMJ Qual Saf 2016;25:556-7.

9 Dixon-Woods M, Baker R, Charles K, et al. Culture and behaviour in the english national health service: overview of lessons from a large multimethod study. BMJ Qual Saf 2014;23:106-15.

10 Millar R, Mannion R, Freeman T, et al. Hospital board oversight of quality and patient safety: a narrative review and synthesis of recent empirical research. Milbank $Q$ 2013;91:738-70.

11 Freeman T, Millar R, Mannion R, et al. Enacting corporate governance of healthcare safety and quality: a dramaturgy of hospital boards in England. Sociol Health Illn 2016;38:233-51.
12 Mannion R, Konteh FH, Davies HT. Assessing organisational culture for quality and safety improvement: a national survey of tools and tool use. Qual Saf Health Care 2009;18:153-6.

13 Jung $\mathrm{T}$, Scott T, Davies H, et al. Instruments for the exploration of organizational culture. Public Adm Rev 2009;69:1987-1096.

14 Scott T, Mannion R, Davies H, et al. The quantitative measurement of organizational culture in health care: a review of the available instruments. Health Serv Res 2003;38:923-45.

15 Mannion R, Davies H. Cultures in Healthcare. In: Ferlie E, Montgomery K, Reff Pedersen A, eds. Oxford handbook of health care management. Oxford: Oxford University Press, 2016.

16 Mannion R, Davies HT, Jacobs R, et al. Do hospital boards matter for better, safer, patient care? Soc Sci Med 2017;177:278-87.

17 Currie G, Dingwall R, Kitchener M, et al. Let's dance: organization studies, medical sociology and health policy. Soc Sci Med 2012;74:273-80. 